\title{
SYNTHESIS OF PHOTOCATALYTIC
}

\section{ANTIFOULING NANOCOMPOSITE MEMBRANE THROUGH MODIFICATION OF CARBON NANOTUBES WITH SEMICONDUCTOR PHOTOCATALYST}

\author{
Farouk Azim Abd Rahman \\ Faculty of Engineering and Green Technology \\ Universiti Tunku Abdul Rahman, Perak, Malaysia
}

\begin{abstract}
This research aims to synthesize nanocomposites through modification of carbon nanotubes with zinc oxide nanopowders by chemical precipitation method in order to investigate their effects on photocatalytic performance. Nanosized zinc-based precipitates were collected and mixed together with chemically oxidized carbon nanotubes in different ratios of CNT/ZnO $\left(1: 2,1: 3\right.$, and 1:4) and calcined at $600{ }^{\circ} \mathrm{C}$. Different calcination temperatures $\left(400{ }^{\circ} \mathrm{C}, 500{ }^{\circ} \mathrm{C}\right.$, and $600{ }^{\circ} \mathrm{C}$ ) were also employed on $\mathrm{CNT} / \mathrm{ZnO}$ of $1: 3$ ratio to investigate the photocatalytic activity. The nanocomposite powders produced were characterized by scanning electron microscopy (SEM), Fourier-transform infrared spectroscopy (FTIR), thermogravimetric analysis (TGA), and particle size analysis. Photocatalytic efficiency was investigated through degradation of Methylene Blue (MB) under sunlight irradiation.
\end{abstract}

Keywords - Photocatalyst, Carbon Nanotubes, CNT, Zinc Oxide, ZnO, Photodegradation, Sol-gel, Chemical Precipitation, Nanocomposite

\section{INTRODUCTION}

Despite photocatalysts having a wide range of uses and advantages, they have limits to their photocatalytic ability, which hinder prolonged use during reactions. The photocatalytic activity of photocatalysts need to overcome factors that are essential for the enhancement of photocatalytic efficiency such as: charge separation which is important in the separation excited electrons from holes to initiate the photocatalytic process; interfacial charge transfer which is important to aid the excitation of electrons from the valence band to the conduction band and avoid electron charges from achieving recombination; and charge carrier recombination that has a low recombination rate to improve the lifetime of photocatalytic activity (Rajeshwar, et al., 2008; Fujishima, Rao, \& Tryk, 2000; Rehman, Ullah, Butt, \& Gohar, 2009).
Metal oxides offer efficient photocatalytic activity while other types of photocatalysts such as metal selenides and metal sulfides are toxic, unstable, and photo-anodic corrosive (Zhou, Qu, Zeida, \& Duan, 2012; Saravanan, Gupta, Narayanan, \& Stephen, 2013; Khan M. M., et al., 2014; Khan M. M., et al., 2014; Khan, Adil, \& Al-Mayouf, Metal oxides as photocatalysts, 2015). $\mathrm{TiO}_{2}, \mathrm{ZnO}$, and $\mathrm{CeO}_{2}$ have similar bandgaps of about $3.32 \mathrm{eV}$. Despite this, due to their high adsorption properties, $\mathrm{CeO}_{2}$ and $\mathrm{ZnO}$ are preferred over $\mathrm{TiO}_{2}$ for the degradation of organic pollutants (ElKhouly, Mohamed, Fathy, \& Fagal, 2017; Saravanan, Thirumal, Gupta, Narayanan, \& Stephen, 2013; Zhang, Yang, Xie, Zhang, \& Li, 2009; Choi, et al., 2016).

Due to their wide bandgaps, $\mathrm{TiO}_{2}$ and $\mathrm{ZnO}$ are inactive under visible light despite being highly evaluated for UV photocatalysis. The ability for hematite to absorb visible light has also generated interest in it as a photocatalytic material. Although, it has lower photocatalytic efficiency due the formation of short-lived metal-to-ligand or ligand-tometal charge transfer states or corrosion property when compared with $\mathrm{TiO}_{2}$ or $\mathrm{ZnO}$ (Fox \& Dulay, 1993). Sunlight consists of mostly $47 \%$ infrared radiation, 5-7\% UV light, and $46 \%$ visible light (Saravanan, Shankar, Prakash, Narayanan, \& Stephen, 2011; Rehman, Ullah, Butt, \& Gohar, 2009; Khan, Adil, \& Al-Mayouf, Metal oxides as photocatalysts, 2015). Efforts are underway to make use of sunlight for energy, water, and environmental solutions. This study suggests achieving higher photocatalytic efficiency of photocatalysts by incorporating them with carbon nanotubes (CNTs).

The chosen method in this study to synthesize zinc oxide as a composite with carbon nanotubes is the chemical co-precipitation method due to its ease of use and ability to be tailored to desired specifications depending on the substance to be used similar to the sol-gel method. The materials needed to use this method are also easily available compared to other methods and a low level of equipment sophistication is needed to conduct this method. The carbon 
nanotubes have the potential to facilitate photogenerated charge separation when incorporated with zinc oxide due to the conductive structure, which could improve photocatalytic efficiency.

\section{METHODOLOGY}

\section{A. Oxidation of CNTs}

The CNTs were oxidized to purify and prepare them for the nanocomposite synthesis. First, $2 \mathrm{~g}$ of raw CNTs were ultrasonicated in $250 \mathrm{ml}$ of concentrated nitric acid $(9.0 \mathrm{M})$ for an hour. Then, the mixture was refluxed at $125^{\circ} \mathrm{C}$ for 6 hours. After being refluxed, the functionalized CNTs were cooled to room temperature before being filtered and washed with distilled water a few times until the $\mathrm{pH}$ was the same as the distilled water and subsequently dried at $60{ }^{\circ} \mathrm{C}$ for 12 hours. The dried CNTs were then grounded into powder form.

\section{B. Synthesis of $\mathrm{CNT} / \mathrm{ZnO}$ Composite}

$5 \mathrm{~g}$ of zinc acetate dihydrate was measured and dissolved in $50 \mathrm{~mL}$ water. Once dissolved, monoethanolamine was added to the solution drop by drop until white precipitate was visible and the solution becomes viscous. The white precipitate was then filtered using a $0.45-\mu \mathrm{m}$ PVDF filtration membrane and washed before being dried at $60^{\circ} \mathrm{C}$. The dried precipitate was subsequently grounded into powder form. Next, the white powder and functionalized CNTs were weighed to have a $\mathrm{CNT} / \mathrm{ZnO}$ mass ratio of $1: 3$.

The two powders were then mixed by stirring and sonicating at $70{ }^{\circ} \mathrm{C}$ with water for 1 hour. The $\mathrm{CNT} / \mathrm{ZnO}$ mixture was then filtered and washed with distilled water and ethanol a few times before being dried at $60{ }^{\circ} \mathrm{C}$ and subsequently grounded into powder. The grounded powder was finally sent for calcination at $600{ }^{\circ} \mathrm{C}$. The steps are repeated for $\mathrm{CNT} / \mathrm{ZnO}$ mass ratios of $1: 2$ and $1: 4$ with $600{ }^{\circ} \mathrm{C}$ calcination temperature and also 2 more sets of $\mathrm{CNT} / \mathrm{ZnO}$ mass ratio of $1: 3$ to be calcined at $400^{\circ} \mathrm{C}$ and $500{ }^{\circ} \mathrm{C}$ respectively. Table-1 and Table-2 show the arranged ratios and calcination temperatures that were varied.

Table-1 Mass ratios of $\mathrm{CNT} / \mathrm{ZnO}$ with Constant Calcination Temperature.

\begin{tabular}{|c|c|}
\hline Mass Ratio of CNT/ZnO & Calcination temperature \\
\hline $1: 2$ & 600 \\
\hline $1: 3$ & 600 \\
\hline $1: 4$ & 600 \\
\hline
\end{tabular}

Table-2 Calcination Temperatures of $\mathrm{CNT} / \mathrm{ZnO}$ with Constant Mass Ratio.

\begin{tabular}{|c|c|}
\hline Mass Ratio of CNT/ZnO & Calcination temperature \\
\hline $1: 3$ & 400 \\
\hline $1: 3$ & 500 \\
\hline $1: 3$ & 600 \\
\hline
\end{tabular}

\section{Fourier Transform Infrared Spectroscopy (FTIR)}

The Spectrum Ex 1 by Perkin Elmer was used to perform the FTIR analysis of the $\mathrm{CNTs}, \mathrm{ZnO}$, and $\mathrm{CNT} / \mathrm{ZnO}$ powders to determine the functional groups in the samples and confirm the $\mathrm{ZnO}$ incorporation into the CNTs. The powders were grinded individually with potassium bromide powder in a 1:10 ratio until mixed uniformly before being compressed into pellets prior to infrared scanning.

\section{Particle Size Analysis (PSA)}

The particle size distribution was measured for each sample by relating the particle sizes to the quantity of sample used in each test in terms of percentage of particle size volume. The cumulative particle size distribution are determined by the volume, area, length, and amounts used when dispersed in the dispersant (distilled water). The Mastersizer 2000, Hydro2000 MU (A) was used to determine the particle size distribution of the $\mathrm{CNT} / \mathrm{ZnO}$ powder.

\section{E. Scanning Electron Microscopy (SEM)}

The morphology of the CNT, ZnO, and CNT/ZnO powders were determined using the JOEL JSM 6701F scanning electron microscope. The samples were placed on a disc and held in place using double-sided carbon tape. They were then coated with platinum particles prior to scanning to avoid sample charging.

\section{F. Thermogravimetric Analysis (TGA)}

The Mettler Toledo TGA SDTA851 E was used to perform the thermogravimetric analysis on the CNT and CNT/ZnO samples to determine their decomposition temperatures. The conditions used are from $25{ }^{\circ} \mathrm{C}$ to $800{ }^{\circ} \mathrm{C}$ in nitrogen atmosphere with a heating rate of $10^{\circ} \mathrm{C} / \mathrm{min}$.

\section{G. Photodegradation Efficiency Test}

Methylene blue was used to test the photodegradation efficiency of the $\mathrm{ZnO} / \mathrm{CNT}$ photocatalyst under sunlight irradiation. $250 \mathrm{~mL}$ of methylene blue was measured at 10 $\mathrm{mg} / \mathrm{L}$ concentration while $1 \mathrm{~g} / \mathrm{L}$ of photocatalyst was weighed. The photocatalyst was poured into the methylene blue solution and stirred at $350 \mathrm{rpm}$ in darkness for 30 minutes. After 30 minutes, a $4 \mathrm{~mL}$ of the methylene blue was extracted for concentration measurement. The methylene blue solution was then stirred under sunlight irradiation. At 30 minute intervals for 3 hours, $4 \mathrm{~mL}$ of methylene blue was extracted for concentration measurement. The concentration was measured using a spectrophotometer. All $\mathrm{CNT} / \mathrm{ZnO}$ samples were tested along with pure $\mathrm{ZnO}$ and no photocatalyst as control experiments. 


\section{$H$. Overall Methodology}

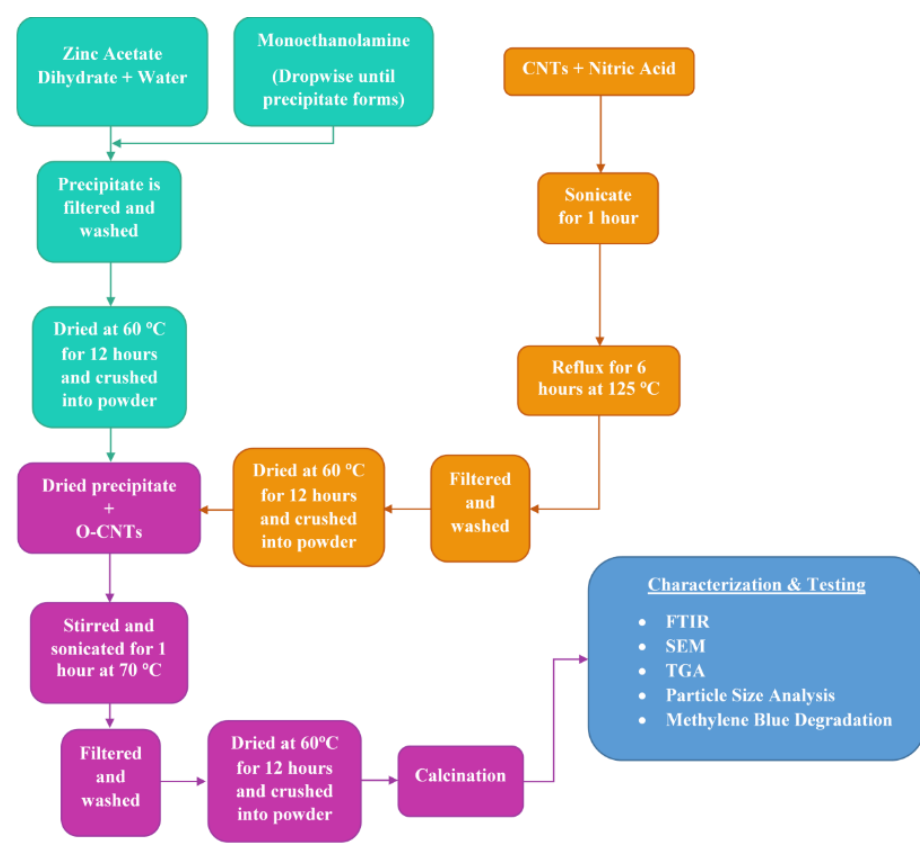

Fig. 1. Overall Methodology Flowchart

\section{RESULTS AND DISCUSSION}

\section{A. Fourier Transform Infrared Spectroscopy (FTIR)}

The graph in Fig. 2 for the raw CNTs shows multiple intensive bands such as at $3448 \mathrm{~cm}^{-1}$ which is attributed to $\mathrm{OH}$ stretching (Stobinski, et al., 2010), and at $1648 \mathrm{~cm}^{-1}$ which indicate $\mathrm{C}=\mathrm{O}$ and $\mathrm{C}=\mathrm{C}$ stretching (Hashwan, et al., 2015; Fatin, et al., 2014). A weak band exists between the $1650 \mathrm{~cm}^{-1}$ and $1450 \mathrm{~cm}^{-1}$ wavelengths that indicate $\mathrm{OH}$ inplane bending (Hashwan, et al., 2015), while bands between the $1300 \mathrm{~cm}^{-1}$ and $1000 \mathrm{~cm}^{-1}$ wavelengths indicate out of plane $\mathrm{OH}$ bending and $\mathrm{C}-\mathrm{O}$ stretching possibly from environmental oxidation (Fatin, et al., 2014; Hashwan, et al., 2015). Oxidation during the manufacturer's purification process or exposure to ambient atmospheric moisture may also have resulted in the $\mathrm{OH}$ stretching at $3448 \mathrm{~cm}^{-1}$ (Aviles, Cauich-Rodriguez, Moo-Tah, May-Pat, \& Vargas-Coronado, 2009).

The functionalized CNTs shown in Fig. 2 reveals that the $\mathrm{OH}$ stretching around $3500 \mathrm{~cm}^{-1}$ and $3400 \mathrm{~cm}^{-1}$ became less intense while the $\mathrm{C}-\mathrm{O}$ stretching intensified at $1136 \mathrm{~cm}^{-1}$. The medium intensity of this band indicates that the oxidation process was incomplete under the acid treatment (Aviles, Cauich-Rodrıguez, Moo-Tah, May-Pat, \& Vargas-Coronado, 2009).

Fig. 3 shows the FTIR spectrum comparisons of the functionalized CNTs, pristine $\mathrm{ZnO}$ powder, and $\mathrm{CNT} / \mathrm{ZnO}$ powder. The broad band peaks from $3400 \mathrm{~cm}^{-1}$ to $3450 \mathrm{~cm}^{-1}$ for all samples indicate $\mathrm{OH}$ stretching of carboxylic group from the CNTs during the functionalization process (Malikov, et al., 2014) and possible adsorbed molecular water
(Largani \& Pasha, 2017). The vibration peaks around the $2970 \mathrm{~cm}^{-1}$ wavelength are assigned to asymmetric C-H stretching (Aviles, Cauich-Rodriguez, Moo-Tah, May-Pat, \& Vargas-Coronado, 2009).

The sharp peak bands between $500 \mathrm{~cm}^{-1}$ to $420 \mathrm{~cm}^{-1}$ and minor bands around $880 \mathrm{~cm}^{-1}$ are characteristic traits of the $\mathrm{Zn}-\mathrm{O}$ and Z-C stretching modes (Largani \& Pasha, 2017). These can be seen in the CNT/ZnO samples but not the CNT sample, which indicates the formation of $\mathrm{ZnO}$ crystals (Amin, Shivaee, Zanetti, Pourjavadi, \& Moshfegh, 2012). It can be observed that there are not much peaks corresponding to the functionalized CNT other than the decreasing intensity of the $\mathrm{OH}$ stretching between $3400 \mathrm{~cm}^{-1}$ to $3450 \mathrm{~cm}^{-1}$. This is possibly because of the low CNT concentration used in the samples (Amin, Shivaee, Zanetti, Pourjavadi, \& Moshfegh, 2012).

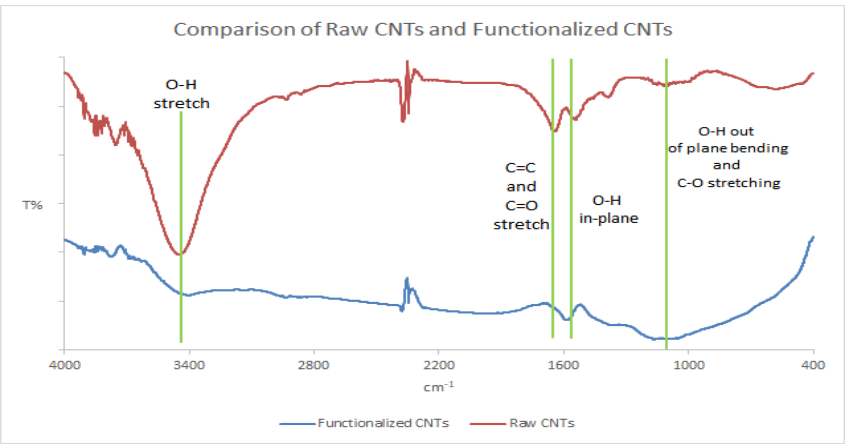

Fig. 2. FTIR of Raw CNTs and Functionalized CNTs

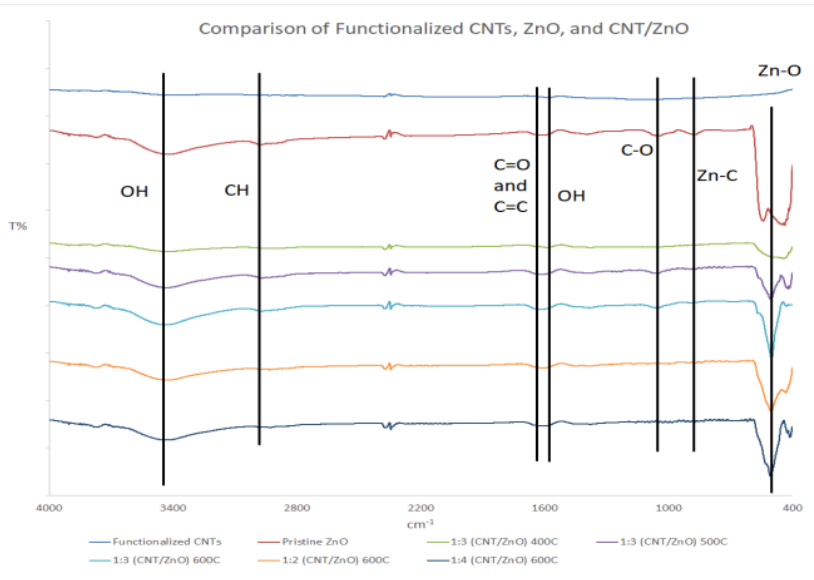

Fig. 3. FTIR of Functionalized CNTs, $\mathrm{ZnO}$, and CNT/ZnO

\section{B. Particle Size Analysis (PSA)}

Particle size analysis was conducted to investigate the mean diameter, specific area, and particle size distribution of the $\mathrm{CNT} / \mathrm{ZnO}$ nano composites. Based on the particle size analysis as observed in Fig. 4 to Fig. 8, CNT/ZnO of 1:3 ratio calcined at $400{ }^{\circ} \mathrm{C}$ exhibited a concentrated distribution 
between 0.040 and 0.275 microns with a minor distribution between 0.55 microns to 1.096 microns. The $\mathrm{CNT} / \mathrm{ZnO}$ with $1: 3$ ratio calcined at $500{ }^{\circ} \mathrm{C}$ exhibited a similar concentrated distribution between 0.040 and 0.275 microns. The distribution of $1: 3 \mathrm{CNT} / \mathrm{ZnO}$ calcined at $600{ }^{\circ} \mathrm{C}$ seems to follow the same concentration area between 0.046 to 0.275 microns. The $1: 4$ and 1:2 $\mathrm{CNT} / \mathrm{ZnO}$ calcined at $600{ }^{\circ} \mathrm{C}$ samples follow similar distributions as the previous samples from 0.040 and 0.275 microns. All samples possess about $12 \%$ to $13 \%$ distribution of the total volumes that are concentrated at around 0.1 microns.

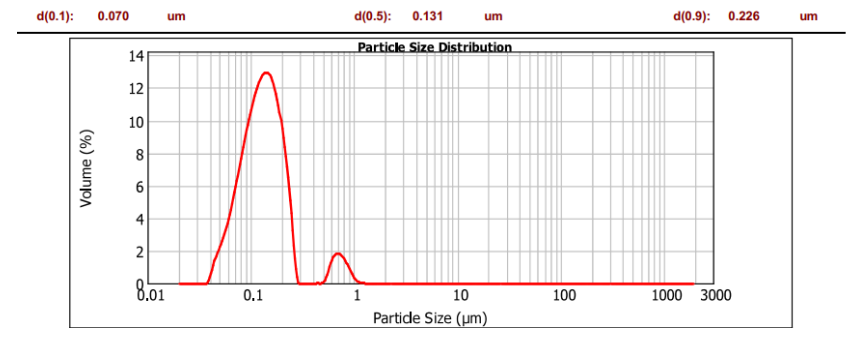

Fig. 4. CNT/ZnO (1:3) Calcined at $400{ }^{\circ} \mathrm{C}$

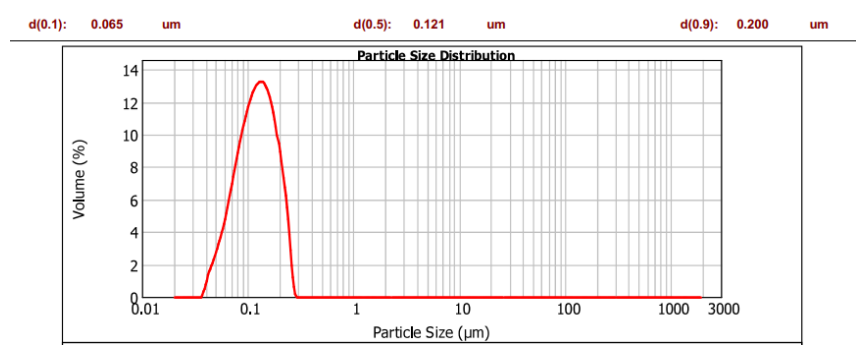

Fig. 5. CNT/ZnO (1:3) Calcined at $500{ }^{\circ} \mathrm{C}$

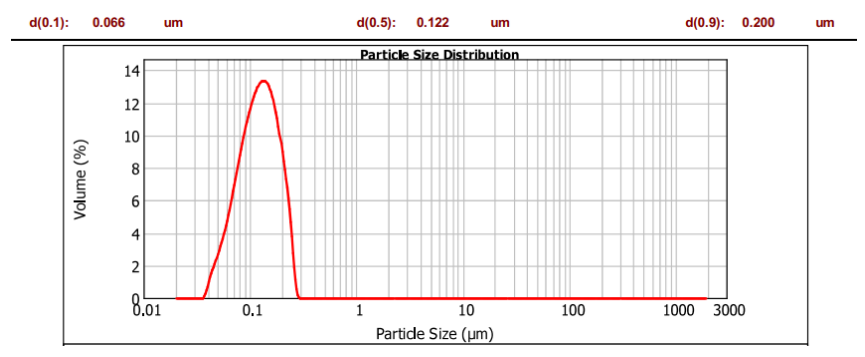

Fig. 6. $\mathrm{CNT} / \mathrm{ZnO}(1: 3)$ Calcined at $600{ }^{\circ} \mathrm{C}$

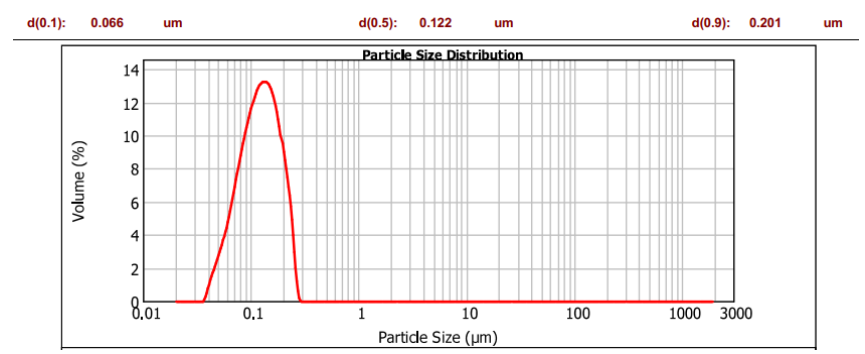

Fig. 7. CNT/ZnO (1:2) Calcined at $600{ }^{\circ} \mathrm{C}$

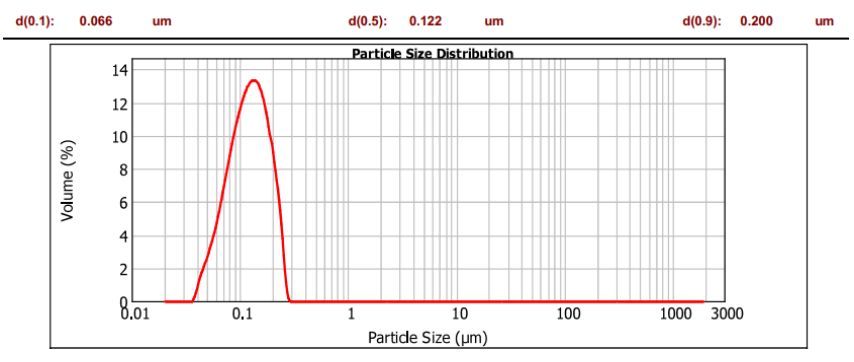

Fig. 8. CNT/ZnO (1:4) Calcined at $600{ }^{\circ} \mathrm{C}$

\section{Scanning Electron Microscopy (SEM)}

The surface morphology, shape, and size of the CNT/ZnO nanocomposites were observed by the use of scanning electron microscopy. Fig. 9 (a) shows the functionalized carbon nanotubes having worm-like bundling structure which is generally unchanged from non-functionalized carbon nanotubes as the long, hollow tube structures are still preserved after acid treatment at short periods (Saeed \& Khan, 2013; Malikov, et al., 2014). The nanoparticles generally seem to have irregular shapes as seen in Fig. 9 (b), (c), (d) and Fig. 10 (e), (f). The samples also displayed various hexagonal wurtzite microrods that are about 1 to 2 microns in length with about 0.5 microns in diameter formed during the $\mathrm{CNT} / \mathrm{ZnO}$ mixing in the presence of water and heat (Pieniążek, Witkowski, Reszka, Godlewski, \& Kowalski, 2016).

It is also observed that only the sample of $1: 3$ $\mathrm{CNT} / \mathrm{ZnO}$ calcined at $400{ }^{\circ} \mathrm{C}$ seen in Fig. 9 (b) contains visible carbon nanotubes surrounding the nanoparticles and microrods while the other samples seem to have similar microrods and almost non-existent visible amounts of carbon nanotubes present possibly due to carbon nanotube decomposition above $420^{\circ} \mathrm{C}$ (Mahajan, Kingon, Kukovecz, Konya, \& Vilarinho, 2013). The small nanoparticles of zinc oxide are mostly about between 50 to 100 nanometres in size from visual inspection of the SEM images. The microrods are likely to decrease the surface area of the overall particles and reduce photocatalytic activity due to less exposed polar facets and oxygen vacancies (Boppella, Anjaneyulu, Basak, \& Manorama, 2013). Fig. 10 (g) shows the pure zinc oxide calcined at $600{ }^{\circ} \mathrm{C}$ with some agglomerated particles. 


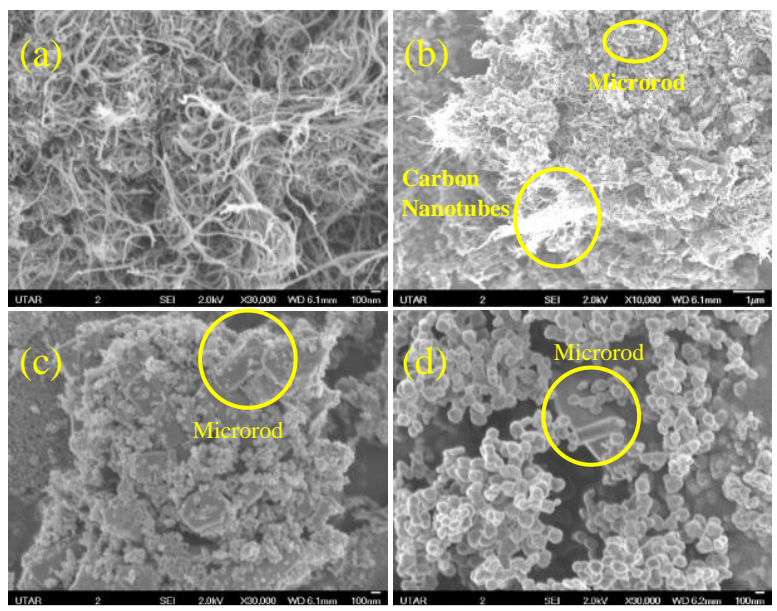

Fig. 9. SEM images of (a) Functionalized CNTs at $\times 30,000$ magnification, (b) $\mathrm{CNT} / \mathrm{ZnO}(1: 3) 400{ }^{\circ} \mathrm{C}$ at $\times 10,000$ magnification, (c) $\mathrm{CNT} / \mathrm{ZnO}(1: 3) 500{ }^{\circ} \mathrm{C}$ at $\times 30,000$ magnification, and (d) $\mathrm{CNT} / \mathrm{ZnO}(1: 3) 600{ }^{\circ} \mathrm{C}$ at $\times 30,000$ magnification.

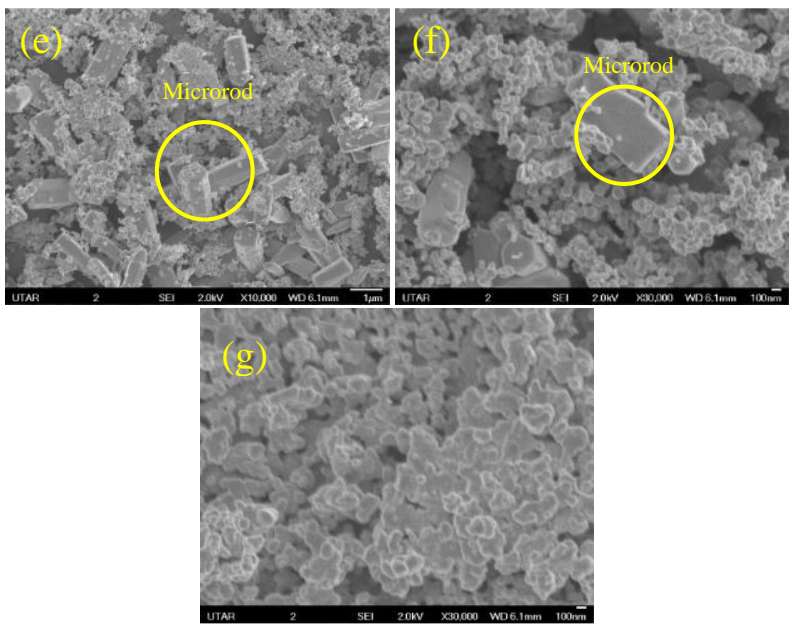

Fig. 10. SEM images of (e) $\mathrm{CNT} / \mathrm{ZnO}(1: 2) 600{ }^{\circ} \mathrm{C}$ at $\times 10,000$ magnification (f) $\mathrm{CNT} / \mathrm{ZnO}(1: 4) 600^{\circ} \mathrm{C}$ at $\times 30,000$ magnification, and (g) $\mathrm{ZnO} 600{ }^{\circ} \mathrm{C} \times 30,000$ magnification.

\section{Thermogravimetric Analysis (TGA)}

Thermogravimetric analysis was conducted to determine the temperature and rate of changes in the mass percentage of the samples prior to being decomposed. It can be observed that the each of the CNT/ZnO samples did not show any significant loss of mass which is exhibited in the constant line as seen in Fig. 11 to 15. This is due to the inert nitrogen gas being used, which did not react with the sample in any way while being heated. It can be assumed that the CNT/ZnO samples were highly stable with little to no decomposition up to $800{ }^{\circ} \mathrm{C}$ or higher in nitrogen gas.

The functionalized CNTs shown in Fig. 16 on the other hand, did show a significant mass drop between $25.4^{\circ} \mathrm{C}$ and $96.5^{\circ} \mathrm{C}$ as well as between $561^{\circ} \mathrm{C}$ and $750{ }^{\circ} \mathrm{C}$. The first drop in mass of $4 \%$ from $25.4{ }^{\circ} \mathrm{C}$ to $96.5^{\circ} \mathrm{C}$ is due to any moisture or impurities in the sample (Le, et al., 2013). After that, a mass drop of $3 \%$ from 561 to $750{ }^{\circ} \mathrm{C}$ is due to the degradation of $\mathrm{COOH}$ group while releasing oxygen, signifying the oxidation of the CNTs (Abuilaiwi, Laoui, AlHarthi, \& Atieh, 2010).

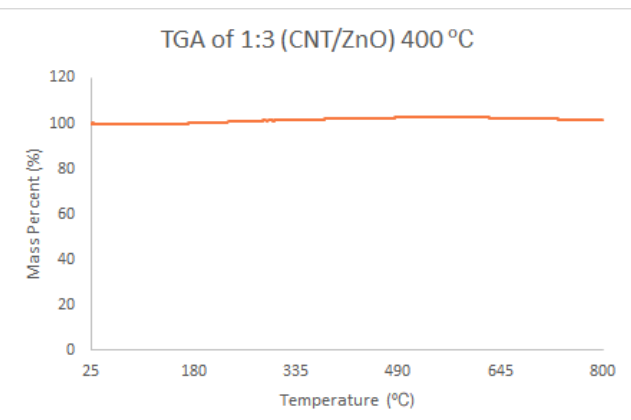

Fig. 11. Thermogravimetric Analysis of CNT/ZnO (1:3) Calcined at $400{ }^{\circ} \mathrm{C}$.

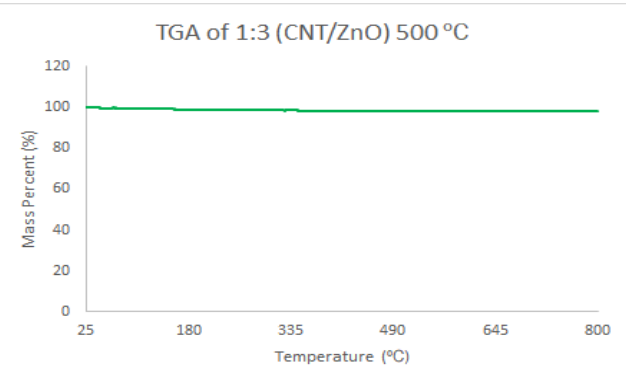

Fig. 12. Thermogravimetric Analysis of $\mathrm{CNT} / \mathrm{ZnO}(1: 3)$ Calcined at $500{ }^{\circ} \mathrm{C}$.

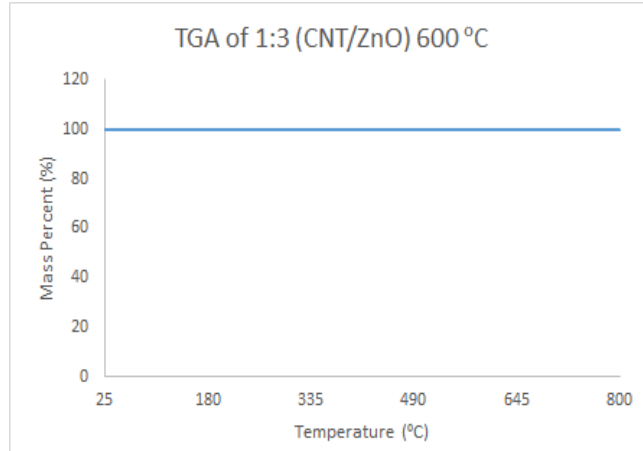

Fig. 13. Thermogravimetric Analysis of $\mathrm{CNT} / \mathrm{ZnO}(1: 3)$ Calcined at $600{ }^{\circ} \mathrm{C}$.

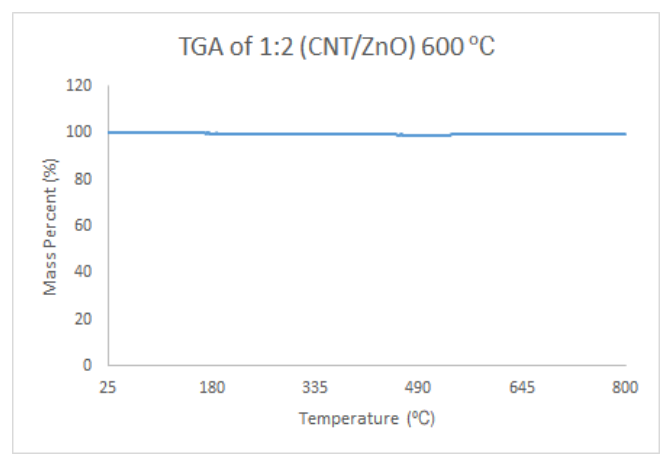


Fig. 14. Thermogravimetric Analysis of CNT/ZnO (1:2) Calcined at $600{ }^{\circ} \mathrm{C}$.

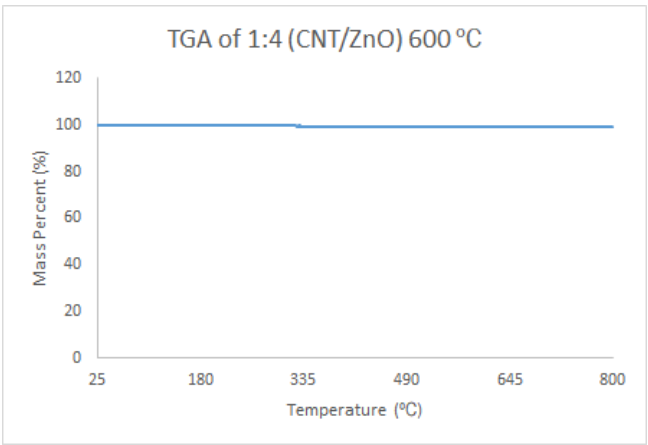

Fig. 15. Thermogravimetric Analysis of CNT/ZnO (1:4) Calcined at $600{ }^{\circ} \mathrm{C}$.

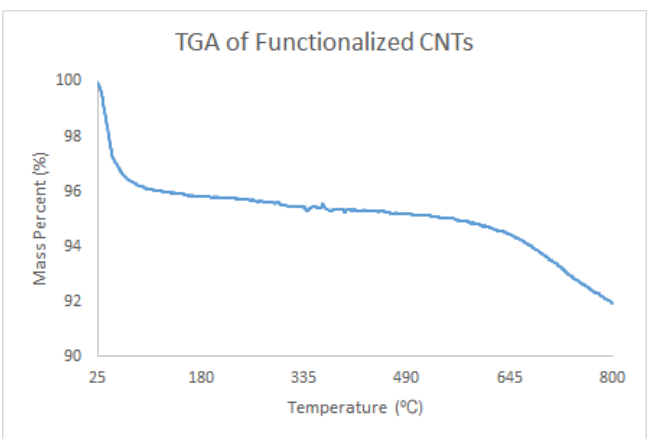

Fig. 16. Thermogravimetric Analysis of Functionalized CNTs.

\section{E. Photodegradation Efficiency Test}

The photocatalytic activity of the $\mathrm{CNT} / \mathrm{ZnO}$ powders were evaluated for methylene blue degradation under sunlight irradiation. The degradation over time was measured by dividing the concentration at each time interval, $\mathrm{C}$ by the initial concentration of the methylene blue, $\mathrm{C}_{0}$. A control test was conducted in the absence of any photocatalyst under sunlight irradiation, which showed that almost no methylene blue degraded. Pure $\mathrm{ZnO}$ calcined at $600{ }^{\circ} \mathrm{C}$ showed $100 \%$ dye degradation after 90 minutes of irradiation. Fig. 17 shows the degradation progression of methylene blue when the $\mathrm{CNT} / \mathrm{ZnO}$ photocatalyst was used while being under 3 hours of sunlight irradiation.

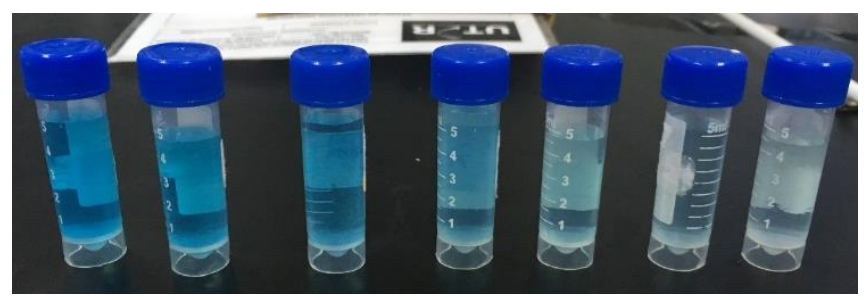

Fig. 17. Methylene Blue Degradation Progression (Initial Concentration from Most Left to Final Concentration on the Most Right).

For the degradation comparisons between the photocatalysts with different ratios of $\mathrm{CNT} / \mathrm{ZnO}$ calcined at $600{ }^{\circ} \mathrm{C}$, only the $1: 4 \mathrm{CNT} / \mathrm{ZnO}$ photocatalyst managed to degrade the methylene blue completely after 180 minutes of irradiation as shown in Fig. 18. The $1: 2 \mathrm{CNT} / \mathrm{ZnO}$ photocatalyst only had a small amount of dye concentration left after 180 minutes of irradiation and was very close to complete degradation. The 1:3 CNT/ZnO photocatalyst on the other hand had $30 \%$ of dye concentration left to degrade at 180 minutes of irradiation. This inconsistent trend of photocatalytic activity between the different $\mathrm{CNT} / \mathrm{ZnO}$ ratios is possibly due to the irregular decomposition of carbon nanotubes as they were all subjected to $600{ }^{\circ} \mathrm{C}$ calcination temperature and different amounts of carbon nanotubes decomposed in each ratio set.

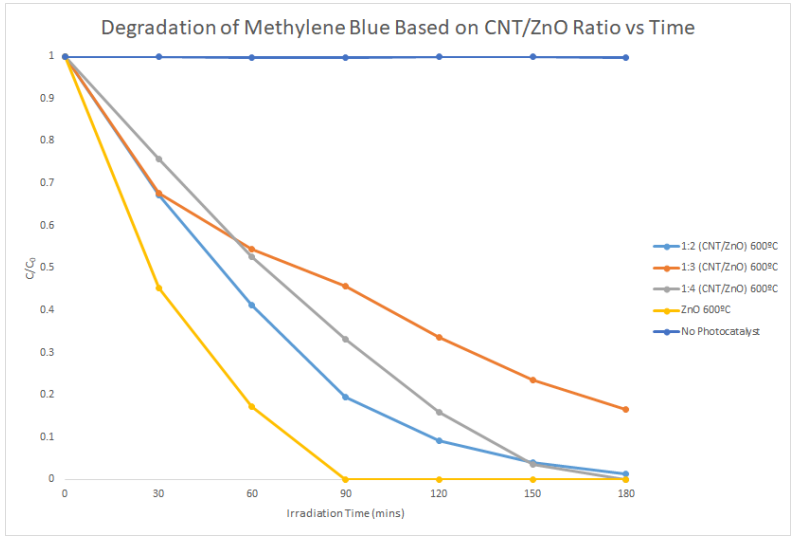

Fig. 18. Degradation of MB based on CNT/ZnO Ratio.

If the carbon nanotubes did not decompose at all or had minimal decomposition during the calcination process, a trend of increasing efficiency should theoretically be shown when the amount of carbon nanotubes to zinc oxide increases until a certain point, where the increase in carbon nanotubes to zinc oxide starts to diminish the performance of the photocatalytic activity (Zhu, et al., 2015; Qusti, 2014; Wang, Yao, \& Li, 2009). A similar trend is said to occur when involving the amount of carbon nanotubes to titanium dioxide (Ahmad, Razali, Mamat, Kassim, \& Amin, 2018), although the opposite also has been reported, where the increase in titanium dioxide to carbon nanotubes increases the photocatalytic efficiency (Abdullahi, Saion, Shaari, Al-Hada, \& Keiteb, 2015).

During degradation comparisons between $\mathrm{CNT} / \mathrm{ZnO}$ calcined at different temperatures, it was observed in Fig. 19 that the photocatalyst with calcined at $400{ }^{\circ} \mathrm{C}$ showed complete dye degradation after 120 minutes of irradiation while the photocatalyst calcined at $500{ }^{\circ} \mathrm{C}$ completely degraded the dye after 150 minutes and the photocatalyst calcined at $600{ }^{\circ} \mathrm{C}$ did not achieve full 
degradation at the end of the test period of 180 minutes, being able to degrade to about $83.5 \%$ of the dye. The decreasing efficiency of the photocatalysts as the calcination temperature increases other than the carbon nanotubes being covered by the $\mathrm{ZnO}$ particles is possibly due to the carbon nanotubes in the nanocomposite decomposing at the higher temperatures as mentioned before.

Although the carbon nanotubes have been said to start decomposing from $650{ }^{\circ} \mathrm{C}$ and above (Xie, Maia, \& Zhou, 2005; Thostenson, Li, \& Chou, 2005; Srikanth, et al., 2016), there are reports of raw single-walled and multiwalled carbon nanotubes decomposing when heated in air above $\sim 400{ }^{\circ} \mathrm{C}$ due to impurities present in the carbon nanotubes (Mahajan, Kingon, Kukovecz, Konya, \& Vilarinho, 2013; Landström, 2016). It has also been mentioned that the functionalization of carbon nanotubes using acid treatments have been shown to lower their thermal properties due to the surface defects induced during functionalization (Kundu, Wang, Xia, \& Muhler, 2008; Luo, et al., 2011; Santangelo, et al., 2014), while it was also reported to instead increase the thermal stability with higher acid concentration during functionalization due to hydrogen bonds forming from the carboxyl group (Hsieh, Chou, Lin, Hsieh, \& Shu, 2010).

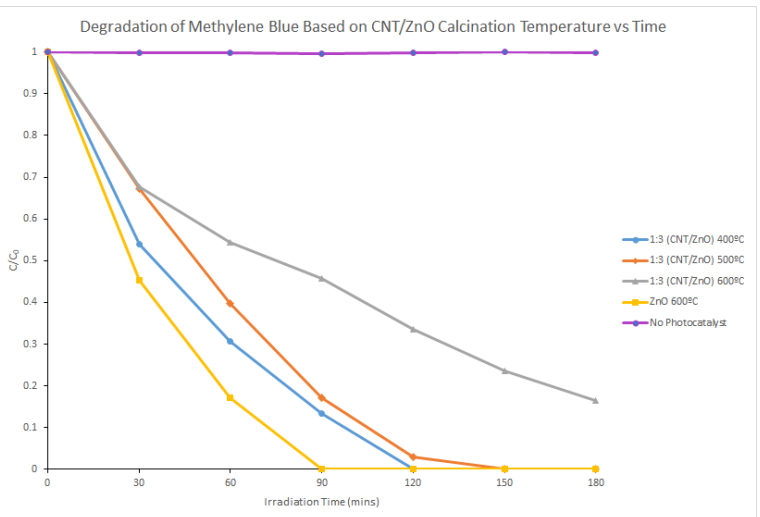

Fig. 19. Degradation of MB based on $\mathrm{CNT} / \mathrm{ZnO}$ Calcination Temperature.

The pure $\mathrm{ZnO}$ photocatalyst calcined at $600{ }^{\circ} \mathrm{C}$ exhibited the highest photocatalytic degradation overall, regardless of $\mathrm{CNT} / \mathrm{ZnO}$ ratio or calcination temperature between the nanocomposites. It is mentioned that the calcination temperature around $600{ }^{\circ} \mathrm{C}$ (Abdullah, So'aib, \& Krishnan, 2017) for 4 hours (Sharma, Kumar, Budhiraja, \& Singh, 2013) has been reported to have good photocatalytic activity with good adsorption ability, better charge transfer rate, and low recombination despite less surface area (Golsheikh, Kamali, Huang, \& Zak, 2017). The presence of $\mathrm{ZnO}$ hexagonal microrods that grew from stirring the $\mathrm{CNT} / \mathrm{ZnO}$ mixture at $70{ }^{\circ} \mathrm{C}$ in the presence of water (Pieniążek, Witkowski, Reszka, Godlewski, \& Kowalski, 2016) during the synthesis process has also contributed in the worsening of the photocatalytic degradation efficiency of
$\mathrm{CNT} / \mathrm{ZnO}$ compared to the pure $\mathrm{ZnO}$ which was not subjected to stirring at $70{ }^{\circ} \mathrm{C}$ in the presence of water at all.

\section{CONCLUSION}

In conclusion, $\mathrm{CNT} / \mathrm{ZnO}$ nanocomposites were synthesized by the chemical co-precipitation method. Nanostructured Znbased precipitate powders were successfully produced by homogeneous precipitation and $\mathrm{CNT} / \mathrm{ZnO}$ nanocomposites fabricated by physically mixing functionalized CNTs with the $\mathrm{Zn}$ nanopowders. The effect of the amount of CNTs to $\mathrm{ZnO}$ ratio and calcination on the properties of the photocatalysts were investigated. Methylene blue degradation test showed that the nanocomposite catalysts showed less efficiency when reacted under sunlight irradiation compared to pure $\mathrm{ZnO}$, largely caused by the formation of microrods during $\mathrm{CNT} / \mathrm{ZnO}$ synthesis mixing and decomposition of CNTs during calcination. CNT/ZnO photocatalyst with 1:4 ratio exhibited highest degradation efficiency compared to other ratios. CNT/ZnO photocatalyst calcined at $400{ }^{\circ} \mathrm{C}$ exhibited highest degradation compared to other calcination temperatures. SEM and FTIR images showed that incorporation of the $\mathrm{ZnO}$ nanoparticles with CNTs to become nanocomposites were confirmed. $\mathrm{ZnO}$ and the carbon nanotube nanocomposites were observed to be thermally stable in nitrogen up to $800{ }^{\circ} \mathrm{C}$. Formations of microrods from the technique used in this study could possibly be applied into other studies regarding microrods and nanorods for other uses.

\section{ACKNOWLEDGEMENT}

The author wishes to express gratitude to Dr Ong Yit Thai and all UTAR lab officers for their support and advices. The author also extends gratitude towards Universiti Tunku Abdul Rahman to allow for this research to happen.

\section{REFERENCES}

Abdullah, N. S., So'aib, S., \& Krishnan, J. (2017). Effect Of Calcination Temperature On Zno/Tio2 Composite In Photocatalytic Treatment Of Phenol Under Visible Light. Malaysian Journal Of Analytical Sciences, 21(1), 173-181.

Abdullahi, N., Saion, E., Shaari, A. H., Al-Hada, N. M., \& Keiteb, A. (2015). Optimisation of the Photonic Efficiency of TiO2 Decorated on MWCNTs for Methylene Blue Photodegradation. Public Library of Science: One, 10(5), 112.

Abuilaiwi, F. A., Laoui, T., Al-Harthi, M., \& Atieh, M. A. (2010). Modification And Functionalization Of Multiwalled Carbon Nanotube (MWCNT) Via FISCHER Esterification. The Arabian Journal for Science and Engineering, 25(10), 37-48. 
Ahmad, A., Razali, M. H., Mamat, M., Kassim, K., \& Amin, K. A. (2018). Physiochemical properties of $\mathrm{TiO} 2$ nanoparticle loaded APTES-functionalized MWCNTs composites and their photocatalytic activity with kinetic study. Arabian Journal of Chemistry, 1-26.

Amin, M. S., Shivaee, H. A., Zanetti, M., Pourjavadi, A., \& Moshfegh, A. Z. (2012). Visible light photocatalytic activity of novel MWCNT doped $\mathrm{ZnO}$ electrospun nanofibers. Journal of Molecular Catalysis A: Chemical, 359, 42-48.

Aviles, F., Cauich-Rodrıguez, J., Moo-Tah, L., May-Pat, A., \& Vargas-Coronado, R. (2009). Evaluation of mild acid oxidation treatments for MWCNT functionalization. Carbon, 47, 2970-2975.

Boppella, R., Anjaneyulu, K., Basak, P., \& Manorama, S. V. (2013). Facile Synthesis of Face Oriented ZnO Crystals: Tunable Polar Facets and Shape Induced Enhanced Photocatalytic Performance. The Journal of Physical Chemistry C, 117, 4597-4605.

Choi, Y. I., Lee, S., Kim, S. K., Kim, Y.-I., Cho, D. W., Khan, M. M., \& Sohn, Y. (2016). Fabrication of ZnO, ZnS, Ag-ZnS, and $\mathrm{Au}-\mathrm{ZnS}$ microspheres for photocatalytic activities, $\mathrm{CO}$ oxidation and 2-hydroxyterephthalic acid synthesis. Journal of Alloys and Compounds, 675, 46-56.

El-Khouly, S. M., Mohamed, G. M., Fathy, N. A., \& Fagal, G. A. (2017). Effect of nanosized $\mathrm{CeO} 2$ or $\mathrm{ZnO}$ loading on adsorption and catalytic properties of activated carbon. Adsorption Science \& Technology, 35(9-10), 774-788.

Fatin, M. F., Ruslinda, A. R., Norhafizah, S., Farehanim, M. A., Arshad, M. K., Ayub, R. M., \& Hashim, U. (2014). Oxidation Functionalization of Multiwalled Carbon Nanotube by Mild Acid Sonication. IEEE Conference on Biomedical Engineering and Sciences, 686-689.

Fox, M. A., \& Dulay, M. T. (1993). Heterogeneous photocatalysis. Chemical Reviews, 93(1), 341-357.

Fujishima, A., Rao, T. N., \& Tryk, D. A. (2000). Titanium dioxide photocatalysis. Journal of Photochemistry and Photobiology C: Photochemistry Reviews, 1(1), 1-21.

Golsheikh, A. M., Kamali, K. Z., Huang, N. M., \& Zak, A. K. (2017). Effect of calcination temperature on performance of $\mathrm{ZnO}$ nanoparticles for dye-sensitized solar cells. Powder Technology, 1-28.

Hashwan, S. S., Fatin, M. F., Ruslinda, A. R., Arshad, M. K., Hashim, U., \& Ayub, R. M. (2015). Functionalization of Multi Wall Carbon Nanotubes Using Nitric Acid Oxidation. Applied Mechanics and Materials, 754-755, 1156-1160.

Hsieh, Y.-C., Chou, Y.-C., Lin, C.-P., Hsieh, T.-F., \& Shu, C.-M. (2010). Thermal Analysis of Multi-walled Carbon Nanotubes by Kissinger's Corrected Kinetic Equation. Aerosol and Air Quality Research, 10, 212-218.
Khan, M. M., Adil, S. F., \& Al-Mayouf, A. (2015). Metal oxides as photocatalysts. Journal of Saudi Chemical Society, 19(5), 462-464.

Khan, M. M., Ansari, S. A., Pradhan, D., Ansari, M. O., Han, D. H., Lee, J., \& Cho, M. H. (2014). Band gap engineered TiO2 nanoparticles for visible light induced photoelectrochemical and photocatalytic studies . Journal of Materials Chemistry A(3), 637-644.

Khan, M. M., Ansari, S. A., Pradhan, D., Han, D. H., Lee, J., \& Cho, M. H. (2014). Defect-Induced Band Gap Narrowed $\mathrm{CeO} 2$ Nanostructures for Visible Light Activities. Industrial \& Engineering Chemistry Research, 53(23), 9754-9763.

Kundu, S., Wang, Y., Xia, W., \& Muhler, p. (2008). Thermal Stability and Reducibility of Oxygen-Containing Functional Groups on Multiwalled Carbon Nanotube Surfaces: A Quantitative High-Resolution XPS and TPD/ TPR Study. The Journal of Physical Chemistry C, 112(43), 16869-16878.

Landström, A. (2016). Thermal Stability of Carbon Nanotubes and Role of Intercalation (Dissertation). Lulea University of Technology, Department of Engineering Sciences and Mathematics, 1-46.

Largani, S. H., \& Pasha, M. A. (2017). The effect of concentration ratio and type of functional group on synthesis of CNT-ZnO hybrid nanomaterial by an in situ sol-gel process. International Nano Letters, 7, 25-33.

Le, V. T., Ngo, C. L., Le, Q. T., Ngo, T. T., Nguyen, D. N., \& Vu, M. T. (2013). Surface modification and functionalization of carbon nanotube with some organic compounds. Advances In Natural Sciences: Nanoscience And Nanotechnology, 4, 1-5.

Luo, Z., Oki, A., Carson, L., Adams, L., Neelgund, G., Soboyejo, N., . . . Traisawatwong, P. (2011). Thermal stability of functionalized carbon nanotubes studied by in-situ transmission electron microscopy. Chemical Physics Letters, 513(1-3), 88-93.

Mahajan, A., Kingon, A., Kukovecz, A., Konya, Z., \& Vilarinho, P. M. (2013). Studies on the thermal decomposition of multiwall carbon nanotubes under different atmospheres. Materials Letters, 90, 165-168.

Malikov, E. Y., Akperov, O. H., Muradov, M. B., Eyvazova, G. M., Maharramov, A. M., \& Kukovecz, Á. (2014). Oxidation of multiwalled carbon nanotubes using different oxidation agents like nitric acid and potassium permanganate. News of Baku University, 4, 49-59.

Pieniążek, A., Witkowski, B. S., Reszka, A., Godlewski, M., \& Kowalski, B. J. (2016). Optical properties of $\mathrm{ZnO}$ microrods grown by a hydrothermal method - a cathodoluminescence study . Optical Materials Express, 6(12), 3741-3750. 
Qusti, A. H. (2014). Fabrication and Characterization of ZnO/MWCNTs with Enhanced Photocatalytic Activity. Asian Journal of Chemistry, 26(16), 4952-4958.

Rajeshwar, K., Osugi, M. E., Chanmanee, W., Chenthamarakshan, C. R., Zanoni, M. V., Kajitvichyanukul, P., \& Krishnan-Ayer, R. (2008). Heterogeneous photocatalytic treatment of organic dyes in air and aqueous media. Journal of Photochemistry and Photobiology C: Photochemistry Reviews, 9(4), 171-192.

Rehman, S., Ullah, R., Butt, A. M., \& Gohar, N. D. (2009). Strategies of making $\mathrm{TiO} 2$ and $\mathrm{ZnO}$ visible light active. Journal of Hazardous Materials, 170(2-3), 560-569.

Saeed, K., \& Khan, I. (2013). Carbon nanotubes-properties and applications: a review. Carbon Letters, 14(3), 131-144.

Santangelo, S., Piperopoulos, E., Rahim, S. H., Faggio, G., Ansari, S., Messina, G., \& Milone, C. (2014). Surface Chemistry and Thermal Stability in Air of Carbon Nanotubes Functionalised via a Novel EcoFriendly Approach to HNO3 Vapor Oxidation. Fullerenes, Nanotubes and Carbon Nanostructures, 23, 83-92.

Saravanan, R., Gupta, V. K., Narayanan, V., \& Stephen, A. (2013). Comparative study on photocatalytic activity of $\mathrm{ZnO}$ prepared by different methods. Journal of Molecular Liquids, 181, 133-141.

Saravanan, R., Shankar, H., Prakash, T., Narayanan, V., \& Stephen, A. (2011). ZnO/CdO composite nanorods for photocatalytic degradation of methylene blue under visible light. Materials Chemistry and Physics, 125(1-2), 277-280.

Saravanan, R., Thirumal, E., Gupta, V. K., Narayanan, V., \& Stephen, A. (2013). The photocatalytic activity of $\mathrm{ZnO}$ prepared by simple thermal decomposition method at various temperatures. Journal of Molecular Liquids, 177, 394-401.

Sharma, A., Kumar, S., Budhiraja, N., \& Singh, R. M. (2013). Effect of calcination on morphology and optical properties of AlO-ZnO nanocomposites. Advances in Applied Science Research, 4(2), 252-258.

Srikanth, I., Padmavathi, N., Prasad, P. S., Ghosal, P., Jain, R. K., \& Subrahmanyam, C. H. (2016). Effect of hightemperature heat treatment duration on the purity and microstructure of MWCNTs. Bulletin of Materials Science, 39(1), 41-46.

Stobinski, L., Lesiak, B., Kövér, L., Tóth, J., Biniak, S., Trykowski, G., \& Judek, J. (2010). Multiwall carbon nanotubes purification and oxidation by nitric acid studied by the FTIR and electron spectroscopy methods. Journal of Alloys and Compounds, 501, 77-84.

Thostenson, E. T., Li, C., \& Chou, T.-W. (2005). Nanocomposites in context. Composites Science and Technology, 65, 491-516.
Wang, X., Yao, S., \& Li, X. (2009). Sol-gel Preparation of CNT/ZnO Nanocomposite and Its Photocatalytic Property. Chinese Journal of Chemistry, 27(7), 1317-1320.

Xie, X.-L., Maia, Y.-W., \& Zhou, X.-P. (2005). Dispersion and Alignment of Carbon Nanotubes in Polymer Matrix: A Review. Materials Science and Engineering: R: Reports, 49(4), 89-112.

Zhang, L., Yang, H., Xie, X., Zhang, F., \& Li, L. (2009). Preparation and photocatalytic activity of hollow $\mathrm{ZnSe}$ microspheres via Ostwald ripening. Journal of Alloys and Compounds, 473(1-2), 65-70.

Zhou, H., Qu, Y., Zeida, T., \& Duan, X. (2012). Towards highly efficient photocatalysts using semiconductor nanoarchitectures. Energy \& Environmental Science(5), 6732-6743.

Zhu, G., Wang, H., Yang, G., Chen, L., Guo, P., \& Zhang, L. (2015). A facile synthesis of $\mathrm{ZnO} / \mathrm{CNTs}$ hierarchical mircosphere composites with enhanced photocatalytic degradation of methylene blue. RSC Advances, 5(89), 7247672481. 